ELECTRONIC LETTER

\title{
Mutations in the FKRP gene can cause muscle-eye-brain disease and Walker-Warburg syndrome
}

\author{
D Beltran-Valero de Bernabé, T Voit, C Longman, A Steinbrecher, V Straub, Y Yuva, R Herrmann, \\ J Sperner, C Korenke, C Diesen, W B Dobyns, H G Brunner, H van Bokhoven, M Brockington, \\ F Muntoni
}

J Med Genet 2004;41:e61 (http://www.jmedgenet.com/cgi/content/full/41/5/e61). doi: 10.1136/jmg.2003.013870

$\mathrm{T}$ he hypoglycosylation of $\alpha$-dystroglycan is a new disease mechanism recently identified in four congenital muscular dystrophies (CMDs): Walker-Warburg syndrome (WWS), muscle-eye-brain disease (MEB), Fukuyama CMD (FCMD), and CMD type IC (MDC 1C). ${ }^{1}$ The underlying genetic defects in these disorders are mutations in known or putative glycosyltransferase enzymes, which among their targets probably include $\alpha$-dystroglycan. FCMD (MIM: 253800 ) is caused by mutations in fukutin ${ }^{2}$; MEB (MEB [MIM 236670]) is due to mutations in $\mathrm{POMGnTl}^{3}$; and in WWS (WWS [MIM: 236670]) POMTl is mutated. ${ }^{4}$ In addition to the brain abnormalities, both MEB and WWS have structural eye involvement. In FCMD, eye involvement is more variable, ranging from myopia to retinal detachment, persistent primary vitreous body, persistent hyaloid artery, or microphthalmos. ${ }^{5}$ WWS, MEB, and FCMD display type II or cobblestone lissencephaly, in which the main abnormality is different degrees of brain malformation secondary at least in part to the overmigration of heterotopic neurones into the leptominenges through gaps in the external (pial) basement membrane. ${ }^{67}$ Whereas there are broad similarities between WWS and MEB, clear diagnostic criteria differentiating between these two conditions have been proposed ${ }^{8}$ and are shown as clinical features in table 1. A similar combination of muscular dystrophy and cobblestone lissencephaly is also found in the myodystrophy mouse (myd, renamed Large ${ }^{\text {myd }}$ ), in which the Large gene is mutated. ${ }^{6}{ }^{10}$ Our group has very recently identified mutations in the human LARGE gene in a patient with a novel form of CMD (MDC1D). ${ }^{11}$

The gene encoding the fukutin related protein (FKRP, [MIM 606612]) is mutated in a severe form of CMD (MDClC, [OMIM 606612]). ${ }^{12}$ Clinical features of MDClC are onset in the first weeks of life, inability to walk, muscle hypertrophy, and highly elevated serum creatine kinase (CK) levels. ${ }^{12}{ }^{13}$ Mutations in the same gene also underlie a milder form of muscular dystrophy (limb girdle muscular dystrophy 2I or LGMD2I), characterised by childhood or adult onset and a relatively benign course, although dilated cardiomyopathy is a common feature [OMIM 607115]. ${ }^{13-15}$ The hypoglycosylation of $\alpha$-dystroglycan is more variable in MDC1C and LGMD2I than that seen in WWS, MEB, and FCMD ${ }^{4-17}$ and, in contrast to the other forms of muscular dystrophy in which $\alpha$-dystroglycan is hypoglycosylated, these patients lack structural brain or eye involvement. This is surprising, since FKRP is expressed in the brain $^{12}$ and $\alpha$-dystroglycan glycosylation is critical for normal brain formation. ${ }^{618}$ Therefore, either the biochemical modification carried out by FKRP is redundant in brain, or the mutations identified in MDC1C and LGMD2I patients may still allow residual FKRP activity that does not fall below a threshold and produce a brain phenotype. We recently described two MDC1C patients with FKRP mutations who also had mild mental retardation

\section{Key points}

- Mutations in putative glycosyltransferases result in hypoglycosylation of $\alpha$-dystroglycan and in muscle, eye, and brain involvement.

- An exception to this rule is the FKRP gene which, when mutated, produces two allelic conditions, MDC1C and LGMD2I, with isolated skeletal muscle involvement.

- We have now identified two patients with muscular dystrophy and severe structural eye and brain malformation, and with novel mutations in the FKRP gene.

- This expands the already wide spectrum of disorders caused by mutations in the FKRP gene, to include conditions such as muscle-eye-brain disease and Walker-Warburg syndrome, in which muscular dystrophy and severe structural brain and eye involvement coexist.

and cystic changes in the cerebellum. ${ }^{19}$ This suggested that some FKRP mutations might also affect the brain. However, the absence of cobblestone lissencephaly and eye involvement clearly differentiated these patients' conditions from MEB and WWS. We now describe two patients from two separate families, with severe structural eye changes and cobblestone lissencephaly. Patient l's illness was diagnosed as MEB, and patient 2 had WWS; both children had homozygous missense FKRP mutations.

\section{CASE REPORTS}

\section{Patient 1}

The first patient (fig 1 and table 1 ) was a boy born at term after an uneventful pregnancy to non-consanguineous German parents. He developed respiratory distress in the neonatal period, requiring ventilation for two days. He was subsequently investigated for muscle hypotonia and roving eye movements at the age of 6 weeks. Serum CK activity was markedly elevated at $3696 \mathrm{U} / \mathrm{l}(\mathrm{nv}<200 \mathrm{U} / \mathrm{l})$. A muscle biopsy showed changes that were suggestive of a muscular dystrophy. There was no muscle available for additional studies. The boy never gained the ability to control his head, sit, or roll over. He showed profound mental retardation and never learned to speak. From the age of 3 years he required tube feeding. Electrocardiography at 3.6 years of age showed left ventricular hypertrophy. He suffered from recurrent pneumonias, and eventually died during a respiratory infection at the age of 7 years.

The boy was clinically blind. Fundoscopic examination showed extreme rarefaction of pigment epithelium, no demarcation of the macula, and a severe myopia bilaterally. At the age of 6 years he developed bilateral retinal 
Table 1 Clinical features of patients 1 and 2, compared with MEB and WWS patients with confirmed mutations in POGnT1 and POMT1, respectively

\begin{tabular}{|c|c|c|c|c|}
\hline Feature * & MEB & WWS & Patient $1 \dagger$ & $\begin{array}{l}\text { Patient } \\
2 \ddagger\end{array}$ \\
\hline $\begin{array}{l}\text { Cortical } \\
\text { abnormality }\end{array}$ & $\begin{array}{l}\text { Pachygyria/ } \\
\text { polymicrogyria }\end{array}$ & $\begin{array}{l}\text { Agyria thin } \\
\text { mantle }\end{array}$ & $\begin{array}{l}\text { FTP } \\
\text { pachygyria }\end{array}$ & Agyria \\
\hline Encephalocele & - & + & - & - \\
\hline Hydrocephalus & ++ & +++ & + & ++ \\
\hline $\begin{array}{l}\text { White matter } \\
\text { abnormality }\end{array}$ & + & +++ & - & + \\
\hline $\begin{array}{l}\text { Fused } \\
\text { hemispheres }\end{array}$ & - & + & - & - \\
\hline Absent septum & - & + & - & + \\
\hline Corpus callosum & Normal/thin & Absent & Normal & Absent \\
\hline $\begin{array}{l}\text { Cerebellar } \\
\text { hypoplasia }\end{array}$ & ++ & +++ & ++ & +++ \\
\hline $\begin{array}{l}\text { Cerebellar } \\
\text { vermis }\end{array}$ & Hypoplastic & Absent & Hypoplastic & Absent \\
\hline Cerebellar cysts & ++ & - & ++ & - \\
\hline $\begin{array}{l}\text { Muscular } \\
\text { dystrophy }\end{array}$ & +++ & +++ & +++ & +r+ \\
\hline Micropthalmia & + & ++ & - & H \\
\hline Retinal defects & ++ & +++ & + & - \\
\hline $\begin{array}{l}\text { Anterior } \\
\text { chamber } \\
\text { abnormalities }\end{array}$ & ++ & +++ & ++ & ++ \\
\hline Life expectancy & $10-30$ years & $<3$ years & 7 years & 3 years \\
\hline \multicolumn{5}{|c|}{$\begin{array}{l}\text { MEB, muscle-eye-brain disease; WWS, Walker-Warburg syndrome; } \\
\text { FTP, fronto, temporal, and parietal. } \\
\text { *The severity of the symptoms grade from - (absent) to +++ (very } \\
\text { pronounced); †MEB phenotype, FKRP mutations; fWWS phenotype, } \\
\text { FKRP mutations. }\end{array}$} \\
\hline
\end{tabular}

detachment, and cryocoagulation of the left eye and vitrectomy of the right eye became necessary. Brain MRI at the age of 7 years showed features suggestive of cobblestone lissencephaly. These included a hypoplastic brainstem and cerebellar vermis with dysplastic foliar pattern, a DandyWalker-like malformation, and moderate hypoplasia and dysplasia of cerebellar hemispheres with multiple cerebellar cortical and subcortical cysts (fig $1 \mathrm{~A}-\mathrm{C}$ ). In addition, a thickened (pachygyric) cortex over the frontal pole and medial aspect of the anterior frontal pole was seen (fig $1 C$ ). The severe eye involvement is also shown (fig $1 D-F$ ). The findings in the right eye after vitrectomy can be appreciated. The signal intensity of the vitreous body of the left eye is also abnormal, slightly increased, as a consequence of a haemorrhage and/or preceding laser coagulation.

\section{Patient 2}

The second patient (fig 2 and table 1)was a girl born to consanguineous Asian parents, briefly described previously as case number II.1 in family \#12 by Cormand, et al. ${ }^{8}$ She presented at birth with marked hypotonia, feeding difficulties, and a congenital hydrocephalus associated with a Dandy-Walker-like malformation. On examination in the first week of life, she had a severe hypotonia with no antigravity movement and absence of head control; she was nasogastrically fed. A very low anterior hairline was observed, together with right sided microphthalmia, corneal clouding, and coloboma, and left sided retinal pigmentary changes. Serum CK was markedly elevated at 15572 UI/l (nv<200 UI/l). A brain MRI showed a large cyst within the posterior fossa of the brain, with splaying of the cerebellar hemispheres. There was absence of the cerebellar vermis, pons hypoplasia, marked dilation of the lateral and third ventricles, and absence of the corpus callosum (fig 2A-D). The white matter signal was increased throughout the supratentorial regions. There was also a complete absence of cortical sulci, indicating lissencephaly. She underwent ventriculoperiteoneal shunting at the age of 5 days, and eventually died at the age of 3 years.
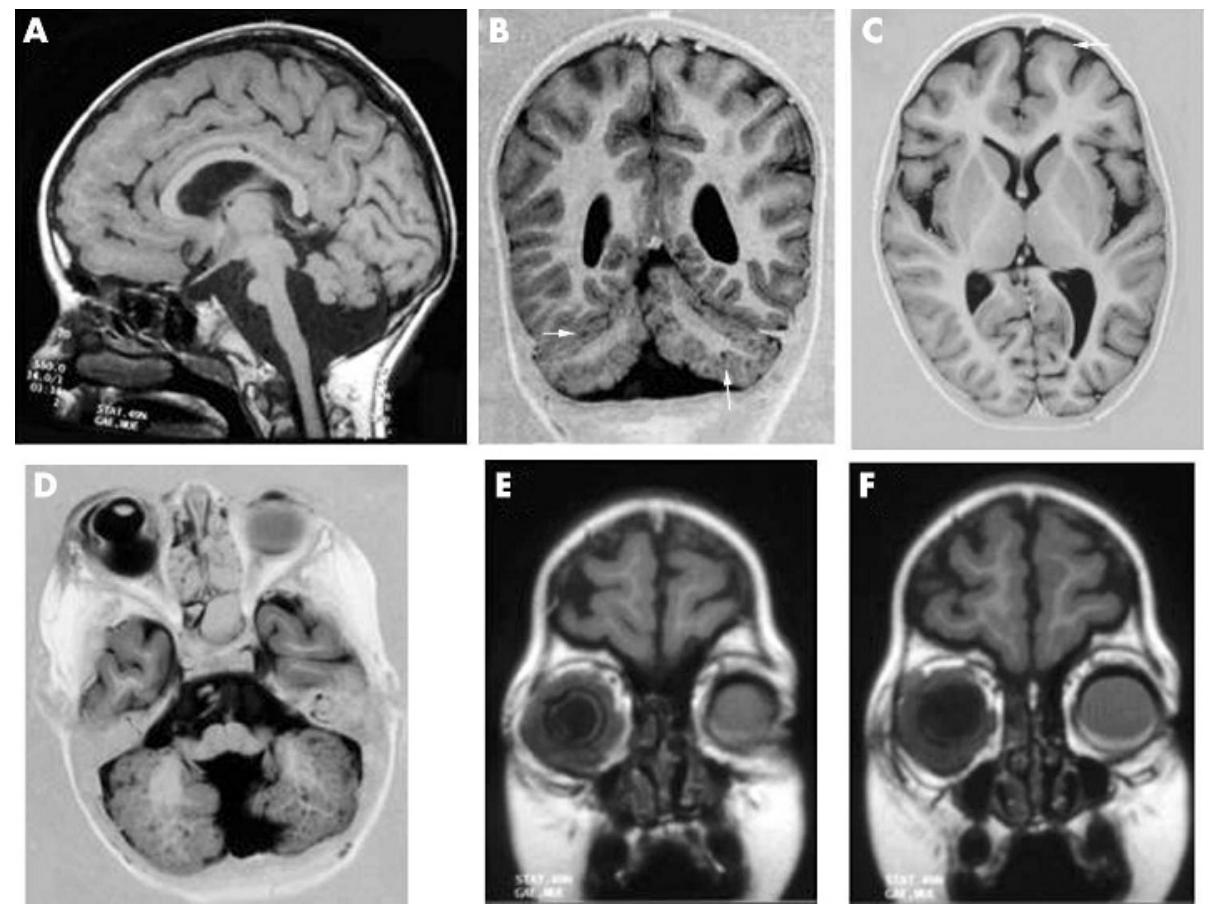

Figure 1 The brain MRI of patient 1 aged 7 years shows changes typical of muscle-eye-brain disease, including thickening (7-8 mm) of the frontal cortex. This features frontal pachygyria (A, arrows in C), mildly simplified gyral pattern with shallow sulci in the posterior temporal and parietal regions, normal white matter, mildly enlarged lateral ventricles, and stretched but otherwise normal corpus callosum. Abnormalities in the posterior fossa include mild hypoplasia of the brainstem, especially the pons (A), severe hypoplasia and dysplasia of the vermis, and mild hypoplasia of the cerebellar hemispheres with scattered small cortical and subcortical cysts (arrows in B; and also evident in C). The fourth ventricle communicates with an enlarged retrocerebellar fluid collection (A, B). The abnormal appearance of both eyes can be clearly seen (D-F). 

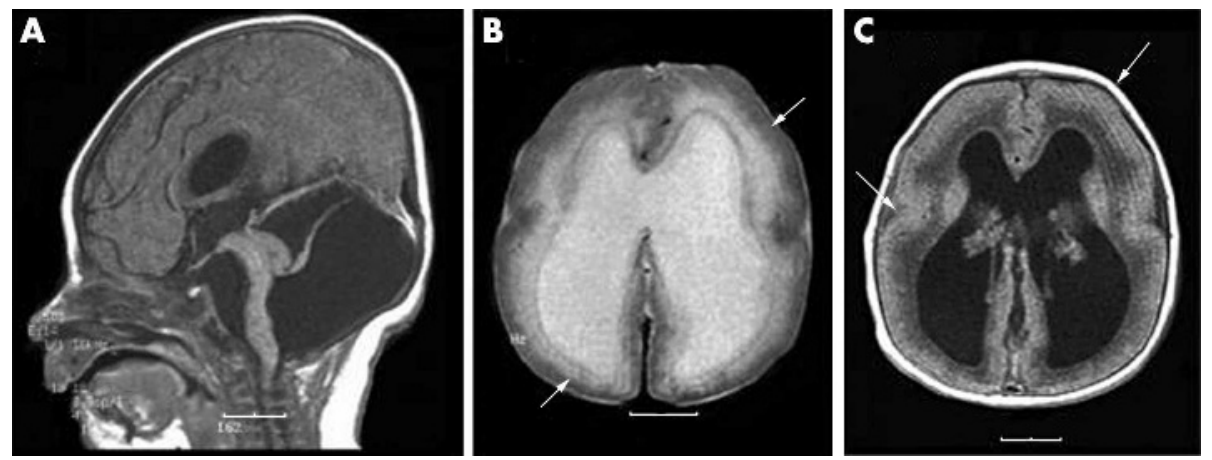

Figure 2 The brain MRI of patient 2 (LP97-123) at 3 days shows diffuse agyria with a thick $1 \mathrm{~cm}$ cortex (arrows in C), discontinuous laminar heterotopia just beneath the cortex (arrows in B), abnormal white matter with high T2 signal, enlarged lateral ventricles, and hypoplastic or possibly absent corpus callosum. The brainstem is small with an enlarged tectum, a mild kink at the midbrain-pons junction, and a very flat pons (A). The kink is less severe than usual for WWS. The cerebellar vermis is severely hypoplastic and the fourth ventricle communicates widely with a retrocerebellar fluid collection (A).

\section{METHODS}

\section{Genetic analysis}

Genetic analysis was performed after obtaining informed consent (HH Trust protocol number 00/5802).

Mutation analysis was carried out by amplifying a $1.7-\mathrm{kb}$ fragment of genomic DNA containing the entire FKRP coding sequence, using Advantage-GC Genomic Polymerase Mix (Clontech, www.clontech.com) and primers FKRP-1F (AAAGGGAATTGAGAAAGAGC) and FKRP-5 (GCTCACAC AGAGCTTCTCC). PCR products were separated by agarose gel electrophoresis, purified (Qiagen, wwwl.qiagen.com) and used for direct sequencing. Sequencing reactions were completed using an ABI Prism BigDye Terminator Cycle Sequencing kit (Applied Biosystems, Foster City, CA) and primers FKRP-1R (GCAGGAAGGAGTCTACCAG), FKRP-2R (CCGAGAGGTTGAAGAGGT), FKRP-3F (AGTTTGTGGCCCT AGTACCT), FKRP-4R (CCTTCTCCCATACGAAGC), and FKRP-5R. Sequencing products were separated on an ABI377 automated sequencer (Applied Biosytems) and analysed using SeqEd (Applied Biosytems).

Linkage analysis to the FKRP locus was determined using flanking markers D19S219 and D19S606. The order of markers was centromere-D19S219-FKRP-D19S606-telomere. Linkage to the MEB locus was determined using flanking markers D9S260 and D9S1793, which lie 3.1 cM centromeric and $3.9 \mathrm{cM}$ telomeric to the locus, respectively. Mutation analysis of the POMTl ${ }^{3}$ and POMGnTl ${ }^{4}$ gene was performed using the genomic primer combinations described by A Yoshiba, et $a l^{3}$ and D Beltran-Valero de Bernabé, et al, ${ }^{4}$ respectively.

\section{RESULTS}

\section{Patient 1}

The original diagnosis in this child was MEB, but it did not link to the POMGnTl locus (not shown). Sequencing of the entire FKRP coding region identified a homozygous T919A missense mutation (fig 3 ). This mutation changes a tyrosine residue at position 307 into an asparagine, and was not found in 200 controls. Tyrosine 307 is conserved in both mouse and rat.

\section{Patient 2}

This child had an original diagnosis of WWS. However, sequence analysis of the POMTl gene did not reveal any mutations, nor was a mutation detected in the POMGnTl gene, although the patient showed homozygosity at this locus as well (not shown). Further linkage analysis to other putative glycosyltransferases was performed in this family, as previously in another 28 WWS families unlinked to the POMT1 locus. ${ }^{4}$ All two families, including family 2 reported in this study, were compatible with linkage to the FKRP locus

A

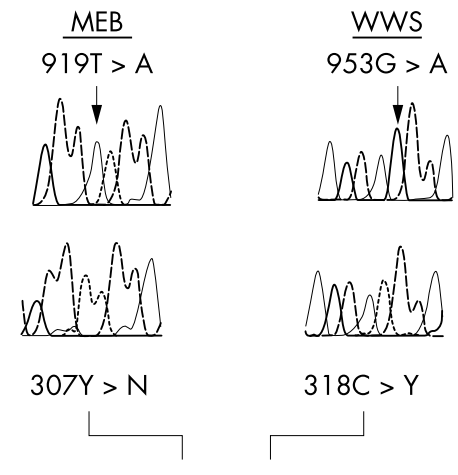

B Fukutin related protein

Wild type

Mutant

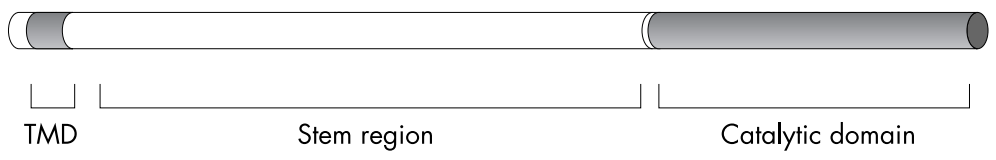

Figure 3 (A) Mutations identified in family 1 and family 2. On the left side the mutation identified in the MEB patient is shown, and on the right side the WWS mutation is represented. Both patients were homozygous for the mutations. The wild type alleles are indicated in the top lane; the mutant alleles below. (B) Schematic representation of the FKRP gene showing the FKRP domains and the location of the residues mutated in the two patients with MEB and WWS. TMD, transmembrane domain. 
(not shown). Sequencing analysis of the FKRP gene identified a novel homozygous C953T missense mutation in patient 2 (fig 3 ). This mutation changes a cysteine at position 318 to tyrosine, and was not found in 200 controls. Cysteine 318 is conserved in both mouse and rat. No mutation in the coding region of the FKRP gene had been found in the other family with a WWS diagnosis linked to the FKRP locus.

\section{DISCUSSION}

These two cases clearly demonstrate that some FKRP mutations can result in structural brain and eye abnormalities. The two patients in this study and the two families with cerebellar cysts reported by Topalolgu, et al ${ }^{19}$ all with central nervous system involvement and FKRP mutations, were homozygous for their respective mutations. The most likely explanation for the brain involvement is that these mutations are more severe and result in more severe disruption of $\alpha$ dystroglycan glycosylation. Although this could not have been formally demonstrated in the patients described in this study, our recent finding that $\alpha$-dystrolgycan was more severely reduced in the patients with MDCIC with cerebellar cysts, ${ }^{19}$ compared with previously noted MDCIC patients without brain involvement, ${ }^{12}$ is consistent with this hypothesis. In this context it is important to note that compound heterozygosity for two null alleles has not been found in FKRP, suggesting that it might not be compatible with life. The mutations associated with brain involvement are not located in a different region of the protein compared with mutations previously reported (fig 3B). ${ }^{12-15}$ The Tyr307Asn mutation has previously been demonstrated in an individual with LGMD2I who was a compound heterozygote for this change and the Leu276Ile mutation. ${ }^{13}$ (This latter mutation is very common in the UK LGMD2I population, and is frequently found homozygously in mildly affected persons. $)^{12-15}$ This individual's relatively mild phenotype was presumably due to the less severe nature of the Leu276Ile mutation. However, the disease course was still unusually severe (the patient died in his early teens), which supports the notion that Tyr307Asn is a particularly severe FKRP mutation. The Cys318Tyr mutation has not been identified previously, and presumably the removal of a cysteine residue, with its ability to form disulphide bridges, has profound consequences on correct protein folding.

Dystroglycan is a peripheral membrane protein of the dystrophin-glycoprotein complex (DGC) common to several tissues, including muscle, nerve, heart, eye, and brain. ${ }^{20-23}$ In skeletal muscle, the DGC links the subsarcolemmal actin associated cytoskeleton to the extracellular matrix, via dystrophin and the laminin $\alpha 2$ chain of laminin $2 .^{24} 25$ Normal dystroglycan expression and the proper glycosylation of its $\alpha$ subunit are required for binding to a number of extracellular ligands, including laminin, neurexin, and agrin. ${ }^{6} 71823$ Disruption of these interactions results in defects of basement membranes in both skeletal muscle and brain. ${ }^{6}$ The integrity of the pial basement membrane, which covers the surface of the brain, is necessary for the organisation of a subpopulation of glial cells, the radial glial cells, which guide the migration of neurones on their inside out journey from the proliferative periventricular regions to the surface of the brain. ${ }^{76} 27$ Defects in the pial basement membrane result in the migration of neurones and glial cells beyond the interrupted pial membrane, giving rise to the cobblestone appearance of the brain. ${ }^{1828} 29$ Cobblestone lissencephaly is a consistent feature of FCMD, MEB, WWS, the Large ${ }^{\text {myd }}$ mouse, and MDCID, but has never been previously described in patients with MDC1C or LGMD2I.

The finding that both MEB and WWS arise from mutations in the FKRP gene further expands the already wide phenotypic spectrum for FKRP mutations. Phenotypic variability, though not as broad as that seen in FKRP, has recently been described in patients with mutations in the fukutin gene. Whereas mutations that give rise to FCMD are predicted to maintain some protein activity, ${ }^{2}$ homozygous null alleles of the fukutin gene give rise to WWS. ${ }^{31}$ The clinical spectrum arising from mutations in POMGTnl is also much wider than was originally appreciated. ${ }^{32}$

Our data now indicate that mutations of the FKRP gene also can disrupt brain structure to a degree most likely depending on the severity of the effect the particular mutation has on protein function. The cobblestone lissencephaly and the structural eye involvement characterise the severe end of the phenotypic spectrum associated with FKRP mutations. Effects range from the catastrophic and early fatal outcome of WWS cases, to the minimal physical disability of patients who remain ambulant in their seventh decade of life. ${ }^{15}{ }^{33}$ Finally, our results suggest that, whereas typical MEB and WWS patients can be distinguished by brain imaging, ${ }^{8}$ they form part of a single disease spectrum resulting from hypoglycosylation of $\alpha$-dystroglycan in which differences in severity are due to the particular disruption that an individual mutation has on the relevant glycosyltransferase.

\section{ACKNOWLEDGEMENTS}

The authors wish to thank the financial support of the Muscular Dystrophy Campaign of the UK (grant to FM), the Alexander Krupp von Bohlen und Halbach Foundation, the Deutsche Forschungsgemeinschaft (Str 498/3-2) to TV, the European Community (Myo-Cluster: GENRE grant QLGl CT 1999 00870) (to FM and TV), the Dutch Foundation for Scientific Research (NWO, 903-42-190) (to HB), the Princess Beatrix Fonds en de Stichting spieren voor spieren (MAR02-0226) (to HVB), and the National Institutes of Health (P01 NS39404) to WBD.

\section{Authors' affiliations \\ D Beltran-Valero de Bernabé*, H G Brunner, H van Bokhoven,}

Department of Human Genetics, University Medical Centre Nijmegen, Netherlands

T Voit', A Steinbrecher, V Straub, R Herrmann, Department of Pediatrics and Pediatric Neurology, University Hospital Essen, Germany C Longman, Y Yuva, M Brockington, F Muntoni, The Dubowitz Neuromuscular Centre, Department of Paediatrics, Imperial College London, UK

J Sperner, Department of Pediatrics, University Hospital Lübeck, Germany

C Korenke, Department of Pediatric Neurology, Staedtische Kliniken Oldenburg, Germany

C Diesen, Folkhalsan Institute of Genetics and Department of Medical Genetics, Haartman Institute, Helsinki, Finland

W B Dobyns, Departments of Human Genetics, Neurology and Pediatrics, University of Chicago, USA

*Both authors have equally contributed to this work Conflicts of interest: none declared.

Correspondence to: F Muntoni, Department of Paediatrics \& Neonatal Medicine, Imperial College London, Hammersmith Hospital Campus, Du Cane Road, London W12 ONN, UK; f.muntoni@imperial.ac.uk

\section{REFERENCES}

1 Muntoni F, Brockington M, Blake DJ, Torelli S, Brown SC. Defective glycosylation in muscular dystrophy. Lancet 2002;360:1419-21

2 Kobayashi K, Nakahori Y, Miyake M, Matsumura K, Kondo-lida E, Nomura Y, Segawa M, Yoshioka M, Saito K, Osawa M, Hamano K, Sakakihara Y Nonaka I, Nakagome Y, Kanazawa I, Nakamura Y, Tokunaga K, Toda T. An ancient retrotransposal insertion causes Fukuyama-type congenital muscular dystrophy. Nature 1998;394:388-92.

3 Yoshida A, Kobayashi K, Manya H, Taniguchi K, Kano H, Mizuno M, Inazu T, Mitsuhashi H, Takahashi S, Takeuchi M, Herrmann R, Straub V, Talim B, Voit T, Topaloglu H, Toda T, Endo T. Muscular dystrophy and neuroneal migration disorder caused by mutations in a glycosyltransferase, POMGnT1. Dev Cell 2001;1:717-24.

4 Beltrán-Valero de Bernabé D, Currier A, Steinbrecher A, Celli J, van Beusekom E, van der Zwaag B, Kayserili H, Merlini L, Chitayat D, Dobyns WB, 
Cormand $\mathrm{B}$, Lehesjoki $\mathrm{AE}$, Cruces J, Voit $\mathrm{T}$, Walsh $\mathrm{CA}$, van Bokhoven $\mathrm{H}$, Brunner HG. Mutations in the O-mannosyltransferase gene POMT1 give rise to the severe neuroneal migration disorder WalkerWarburg syndrome. Am J Hum Genet 2002;71:1033-43.

5 Hino N, Kobayashi M, Shibata N, Yamamoto T, Saito K, Osawa M. Clinicopathological study on eyes from cases of Fukuyama type congenital muscular dystrophy. Brain Dev $2001 ; 23: 97-107$

6 Michele DE, Barresi R, Kanagawa M, Saito F, Cohn RD, Satz J, Dollar J, Nishino I, Kelley RI, Somer H, Straub V, Mathews KD, Moore SA Campbell KA. Post-translational disruption of dystroglycan-ligand interactions in congenital muscular dystrophies. Nature 2002;418:422-5.

7 Montanaro F, Carbonetto S. Targeting dystroglycan in the brain. Neurone 2003:37:193-6.

8 Cormand B, Pihko H, Bayes M, Valanne L, Santavuori P, Talim B, GershoniBaruch R, Ahmad A, van Bokhoven H, Brunner HG, Voit T, Topaloglu H, Dobyns WB, Lehesjoki AE. Clinical and genetic distinction between WalkerWarburg syndrome and muscle-eye-brain disease. Neurology 2001;56:1059-69.

9 Grewal PK, Holzfeind PJ, Bittner RE, Hewitt JE. Mutant glycosyltransferase and altered glycosylation of alpha- dystroglycan in the myodystrophy mouse. Nat Genet 2001;28:151-4.

10 Holzfeind PJ, Grewal PK, Reitsamer HA, Kechvar J, Lassmann H, Hoeger H, Hewitt JE, Bittner RE. Skeletal, cardiac and tongue muscle pathology, defective retinal transmission, and neuroneal migration defects in the Large(myd) mouse defines a natural model for glycosylation-deficient muscle-eye-brain disorders. Hum Mol Genet 2002; 1 1:2673-87.

11 Brockington M, Blake DJ, Prandini P, et al. Mutations in the fukutin-related protein gene (FKRP) cause a form of congenital muscular dystrophy with secondary laminin alpha2 deficiency and abnormal glycosylation of alphadystroglycan. Am J Hum Gen 2001;69:1198-209.

12 Longman C, Brockingtom M, Torelli S, Jimenez-Mallebrera C, Kennedy C, Khalil N, Feng L, Saran RK, Voit T, Merlini L, Sewry CA, Brown SC, Muntoni F. Mutations in the human LARGE gene cause MDC1D, a novel form of congenital muscular dystrophy with severe mental retardation and abnormal glycosylation of $\alpha$-dystroglycan. Hum Mol Genet 2003;12(21):2853-61.

13 Mercuri E, Brockington M, Straub V, Quijano-Roy S, Yuva Y, Herrmann R, Brown SC, Torelli S, Dubowitz V, Blake DJ, Romero NB, Estournet B, Sewry CA, Guicheney P, Voit T, Muntoni F. Phenotypic spectrum associated with mutations in the fukutin-related protein gene: from severe congenital onset to limb girdle muscular dystrophy. Ann Neurol 2003;53:537-42.

14 Brockington M, Yuva Y, Prandini P, et al. Mutations in the Fukutin RelatedProtein gene (FKRP) identifies Limb Girdle Muscular Dystrophy 21 as a milder allelic variant of congenital muscular dystrophy MDC1C. Hum Mol Gen 2001; 10:2851-9.

15 Poppe M, Cree L, Bourke J, Eagle M, Anderson LV, Birchall D, Brockington M, Buddles M, Busby M, Muntoni F, Wills A, Bushby K. The phenotype of limb girdle muscular dystrophy type 2l. Neurology 2003;60:1246-51.

16 Hayashi YK, Ogawa M, Tagawa K, et al. Selective deficiency of alphadystroglycan in Fukuyama-type congenital muscular dystrophy. Neurology 2001;57:115-21.

17 Kano H, Kobayashi K, Herrmann R, et al. Deficiency of alpha-Dystroglycan in Muscle-Eye-Brain Disease. Biochem Biophys Res Commun 2002;291:1283-6.
18 Moore SA, Salto F, Chen J, Michelle DE, Henry MD Messing A, Cohn RD, Ross-Barta SE, Westra S, Williamson RA, Hoshi T, Campbell KP. Deletion of brain dystroglycan recapitulates aspects of congenital muscular dystrophy. Nature 2002:418:417-22.

19 Topaloglu H, Brockington M, Yuva Y, Talim B, Haliloglu G, Blake D, Torelli S, Brown SC, Muntoni F. FKRP gene mutations cause congenital muscular dystrophy, mental retardation, and cerebellar cysts. Neurology 2003;60:988-92

20 Henry MD, Campbell KP. Dystroglycan inside and out. Curr Opin Cell Biol 1999;11:602-7.

21 Moukhles H, Roque R, Carbonetto S. Alpha-dystroglycan isoforms are differentially distributed in adult rat retina. J Comp Neurol 2000;420:182-94.

22 Winder SJ. The complexity of dystroglycan. Trends Biochem Sci 2001;26:118-24.

23 Michele DE, Campbell KP. Dystrophin-glycoprotein complex: posttranslational processing and dystroglycan function. J Biol Chem 2003;278: 15457-60.

24 Ervasti JM, Campbell KP. Membrane organization of the dystrophinglycoprotein complex. Cell 1991;66:1121-31.

25 Ibraghimov-Beskrovnaya O, Ervasti JM, Leveille CJ, Slaughter CA, Sernett SW, Campbell KP. Primary structure of dystrophin-associated glycoproteins linking dystrophin to the extracellular matrix. Nature 1992;355:696-702.

26 Ross ME, Walsh CA. Human brain malformations and their lessons for neuroneal migration. Annu Rev Neurosci 2001;24:1041-70.

27 Kato M, Dobyns WB. Lissencephaly and the molecular basis of neuroneal migration. Hum Mol Genet 2003; 12:R89-96.

28 Dobyns WB, Truwit CL. Lissencephaly and other malformations of cortical development: 1995 update. Neuropediatrics 1995;26:132-47.

29 Saito Y, Murayama S, Kawai M, Nakano I. Breached cerebral glia limitansbasal lamina complex in Fukuyama-type congenital muscular dystrophy. Acta Neuropathol 1999;98:330-6.

30 Silan F, Yoshioka M, Kobayashi K, Simsek E, Tunc M, Alper M, Cam M Guven A, Fukuda Y, Kinoshita M, Kocabay K, Toda T. A new mutation of the fukutin gene in a non-Japanese patient. Ann Neurol 2003;53:392-6.

31 Beltrán-Valero de Bernabé $D$, van Bokhoven $H$, van Beusekom $E$, Van den Akker W, Kant S, Dobyns B, Currier S, Hamel B, Talim B, Topaloglu H, Brunner HG. A homozygous nonsense mutation of the Fukutin gene causes a WalkerWarburg Syndrome phenotype. J Med Genet 2003;40:845-8.

32 Taniguchi K, Kobayashi K, Saito K, Yamanouchi H, Ohnuma A, Hayashi YK, Manya $\mathrm{H}$, Jin DK, Lee M, Parano E, Falsaperla R, Pavone P, Van Coster R, Talim B, Steinbrecher A, Straub V, Nishino I, Topaloglu H, Voit T, Endo T, Toda T. Distribution and broader clinical spectrum of muscle-eye-brain disease. Hum Mol Genet 2003; 12:527-34.

33 Muntoni $F$, Valero de Bernabe B, Bittner R, Blake D, van Bokhoven $\mathrm{H}$ Brockington M, Brown S, Bushby K, Campbell KP, Fiszman M, Gruenewald S, Merlini L, Quijano-Roy S, Romero N, Sabatelli P, Sewry CA, Straub V, Talim B, Topaloglu H, Voit T, Yurchenco PD, Urtizberea JA, Wewer UM, Guicheney P. 114 th ENMC International Workshop on Congenital Muscular Dystrophy (CMD) 2003, Naarden, Netherlands; 8th Workshop of the Internationa Consortium on CMD; 3rd Workshop of the MYO-CLUSTER project GENRE. Neuromuscul Disord 2003; 13:579-88. 